\title{
Necrotizing fasciitis as a complication of taxanes: a case report
}

\author{
Nasser Mohammed Amer, Rabia Niaz \\ Department of General Surgery, King Fahad Hospital of the University, Imam Abdulrahman Bin Faisal University, Al Khobar \\ 34445, Saudi Arabia.
}

Correspondence to: Dr. Nasser Mohammed Amer, Department of General Surgery, King Fahad Hospital of the University, Imam Abdulrahman Bin Faisal University, Al Khobar 34445, Saudi Arabia. E-mail: Nasser@nasseramer.com

How to cite this article: Amer NM, Niaz R. Necrotizing fasciitis as a complication of taxanes: a case report. J Cancer Metastasis Treat2018;4:34. http://dx.doi.org/10.20517/2394-4722.2018.09

Received: 5 Feb 2018 First Decision: 26 Mar 2018 Revised: 28 Mar 2018 Accepted: 6 Jun 2018 Published: 17 Jul 2018

Science Editor: Lucio Miele Copy Editor: Jun-Yao Li Production Editor: Cai-Hong Wang

\begin{abstract}
Necrotizing fasciitis is a rare complication of chemotherapy, however, few reports were published as a specific complication of taxanes. We are reporting this rare complication of a lady who was treated with taxanes as an adjuvant therapy for her breast cancer who was referred to us from the medical department and turned out to be necrotizing fasciitis in her right thigh. We are also presenting the literature review of this type of complication.
\end{abstract}

Keywords: Necrotizing fasciitis, breast cancer, taxanes, docetaxel, complication of chemotherapy

\section{INTRODUCTION}

Necrotizing fasciitis is a rare complication of chemotherapy. It is characterized by necrosis of the soft tissue subcutaneous fat and fascia. Necrotizing fasciitis secondary to taxanes alone is very rare, and only 7 cases have been reported by the WHO adverse drug reactions ${ }^{[1]}$. Taxanes, however, as a chemotherapy, has been used as an adjuvant treatment in combination with other chemotherapy like fluorouracil and cyclophosphamide with reduction of the risk of recurrence by $25 \%$ and death by $17 \%$. Many complications have been reported from the minor nausea, vomiting, alopecia, neuropathy to the development of secondary malignancy. Depression of the immune system is one of the most worrying side effects where patients become prone to develop all spectrums of infections, including necrotizing fasciitis as in our case. We are presenting this case in order to highlight the presence of this complication despite its rarity.

\footnotetext{
(c) (7)

(C) The Author(s) 2018. Open Access This article is licensed under a Creative Commons Attribution 4.0 International License (https://creativecommons.org/licenses/by/4.0/), which permits unrestricted use, sharing, adaptation, distribution and reproduction in any medium or format, for any purpose, even commercially, as long as you give appropriate credit to the original author(s) and the source, provide a link to the Creative Commons license, and indicate if changes were made.
}

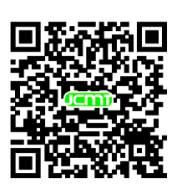




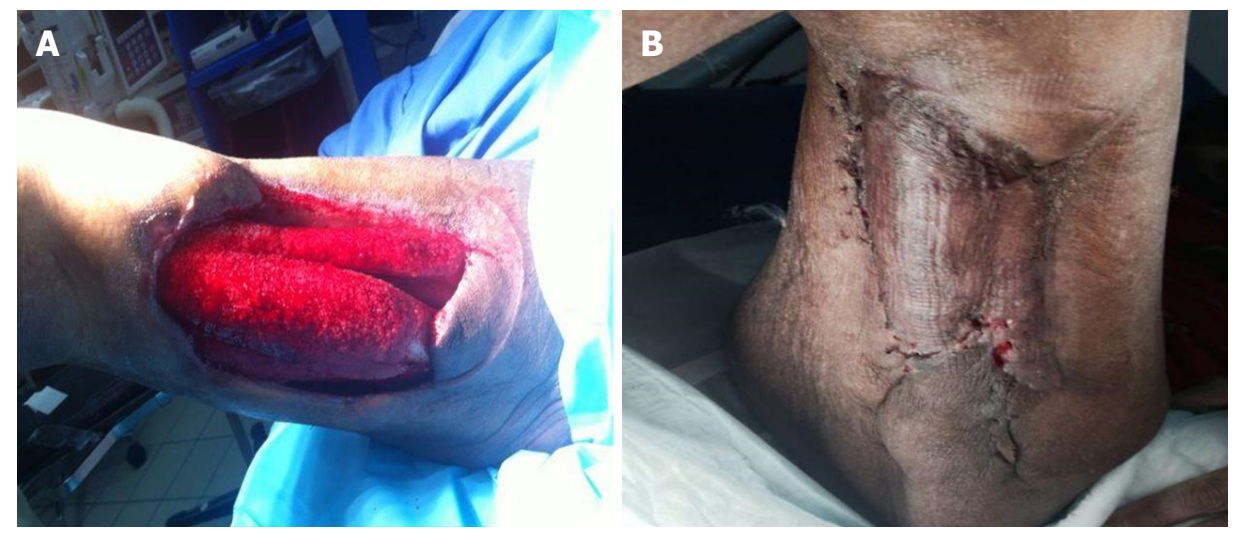

Figure 1. (A) Post debridement; (B) post skin grafting

\section{CASE REPORT}

A 52-year-old female presented to our emergency department complaining of painful right lower limb swelling, generalized weakness and fever for 2 days. There were no history of trauma, intervention or insect bites and no other chronic medical illness. The lady was diagnosed with breast cancer 6 months prior to this admission and she had breasts conserving wide local excision of the tumor, followed by 7 cycles of adriamycin and cyclophosphamide, then 3 cycles of docetaxel. The last cycle of the taxane was just 12 days prior to her admission. On examination, she looked unwell, tachycardia with generalized swelling and tenderness in the medial aspect of the right thigh. There was no distal neurovascular compromise and no palpable lymphadenopathy. Her complete blood picture and inflammatory markers were normal on admission.

Following aggressive resuscitation in the intensive care unit, she was taken to the operating theatre where extensive debridement of necrotic tissue was done from the right thigh. This was repeated four times on different occasions till nice granulation tissue was obtained, which was then covered by split skin graft [Figure 1]. The histopathology features showed focal ulceration, marked hemorrhage, congestion, full thickness necrosis, fibro purulent exudate and micro abscesses formation along with degenerating muscle fibers consistent with necrotizing fasciitis.

\section{DISCUSSION}

Necrotizing fasciitis is an uncommon infection with high mortality rate ${ }^{[2]}$ caused by wide spectrum of micro-organisms, of which two thirds are polymicrobial (type A) and one third is monomicrobial, mainly cocci (type B $)^{[3]}$. It involves inflammation and necrosis of subcutaneous tissue, fascia, and muscles and later of skin. High index of suspicion is needed for early diagnosis. Appearance of swelling, tachycardia, tense oedema, ecchymosis, blister or bullae, crepitus and hypotension are late signs $\mathrm{s}^{[4]}$.

Scoring system suggested by Wong et al.$^{[5]}$ based on the level of haemoglobin, leucocyte count, C reactive protein, creatinine, glucose, and sodium will aid with the diagnosis. Diagnosis, however, is usually confirmed intraoperatively when we find the classical foul smell "dish water" discharge, necrosis with positive "finger test".

Aggressive and radical debridement is critical for improving the outcome and lowering mortality rate ${ }^{[6]}$.

In our patient, there was no other predisposing factor found for the development of necrotizing fasciitis apart from the fact that the patient was on docetaxel at the time of infection, where she received 3 cycles 12 days 
prior to admission. It has been documented that chemotherapy leading to alterations on the mucosa, softtissue, and skin along with immunosuppression might be a triggering factor ${ }^{[7]}$. The skin toxicity (including dry skin, erythema, pigmentation, pruritus, rash/desquamation, urticaria, dermatitis, and other) has been reported in previous studies ${ }^{[8]}$. It was hypothesized that taxanes metabolites are excreted through the sweat glands which are abundant on the palms and soles.

The WHO however, reported in their adverse drug reaction database only 7 cases of necrotizing fasciitis associated with docetaxel.

To conclude, we should always have a low threshold point in suspecting necrotizing fasciitis when reviewing patients presenting with pain while on chemotherapy. Also, keeping in mind that patients can appear systemically well despite the presence of necrotizing fasciitis due to immune suppression - as these patients are not able to respond to infection adequately and skin manifestation may present different due to their blunted immunological response system.

\section{DECLARATIONS}

\section{Authors' contributions}

Assisted in collection of the data and the patients' notes from the file, refined the literature and wrote the paper: Amer NM

Did the primary collection of the patients' notes, lab results and the photos, collected the literature and assisted with the writing of the manuscript: Niaz R

\section{Availability of data and materials}

All data and information are available from the corresponding author upon request.

\section{Financial support and sponsorship}

None.

\section{Conflicts of interest}

The authors declare that there are no conflicts of interest.

\section{Ethical approval and consent to participate}

Not applicable since it is only a case report and not a study.

\section{Consent for publication}

Patient gave full informed consent for writing and publishing this paper.

\section{Copyright}

(c) The Author(s) 2018.

\section{REFERENCES}

1. Editorial comment. First report of necrotizing fasciitis during concomitant radiotherapy: case report. Reactions 2007;1172:10.

2. Brumann M, Bogner V, Völkl A, Sotlar K, Euler E, Mutschler W. Necrotizing fasciitis in a young patient with acute myeloid leukemia a diagnostic challenge. Patient Saf Surg 2014;8:28.

3. Anaya DA, Dellinger EP. Necrotizing soft-tissue infection: diagnosis and management. Clin Infect Dis 2007;44:705-10.

4. Vijayakumar A, Pullagura R, Thimmappa D. Necrotizing fasciitis: diagnostic challenges and current practices. ISRN Infect Dis 2014;2014:208072.

5. Wong CH, Khin LW, Heng KS, Tan KC, Low CO. The LRINEC (laboratory risk indicator for necrotizing fasciitis) score: a tool for 
distinguishing necrotizing fasciitis from other soft tissue infections. Crit Care Med 2004;32:1535-41.

6. Mackay HJ, Williamson EC, Vasey P, Harriett AN. Recurrent inflammation in a site of previous necrotizing fasciitis during intravenous CMF chemotherapy. Ann Oncol 1999;10:1101-3.

7. Maluf FC, William WN Jr, Rigato O, Menon AD, Parise O Jr, Docema MF. Necrotizing fasciitis as a late complication of multimodal treatment for locally advanced head and neck cancer: a case report. Head Neck 2007;29:700-4.

8. Poi MJ, Berger M, Lustberg M, Layman R, Shapiro CL, Ramaswamy B, Mrozek E, Olson E, Wesolowski R. Docetaxel-induced skin toxicities in breast cancer patients subsequent to paclitaxel shortage: a case series and literature review. Support Care Cancer 2013;21:2679-86. 